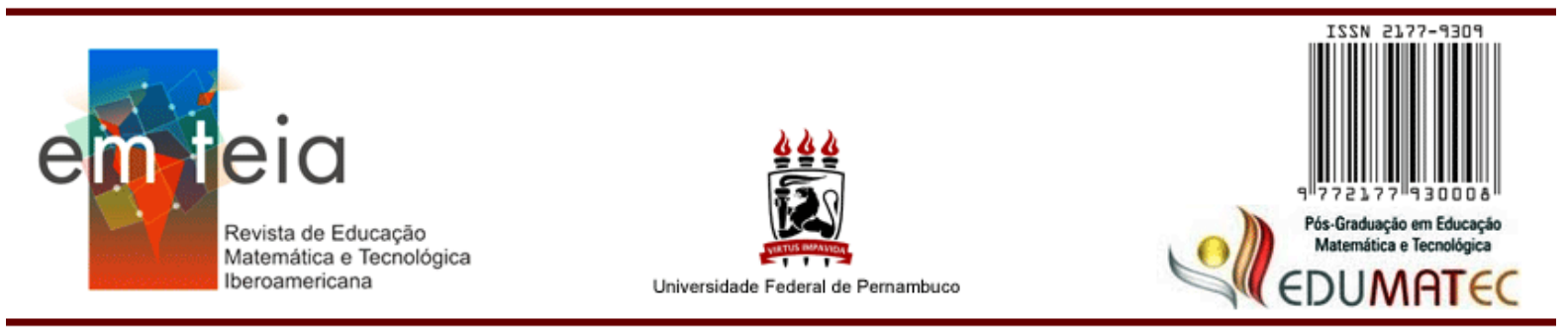

\title{
ANÁLISE DE ERROS EM QUESTÕES SOBRE SEQUÊNCIAS NUMÉRICAS: UMA CONTRIBUIÇÃO PARA A FORMAÇÃO DO PROFESSOR DE MATEMÁTICA
}

\section{Miriam Ferrazza HECK ${ }^{1}$}

No primeiro capítulo da dissertação, a autora apresenta o cenário da investigação de forma a introduzir seu estudo, apresentando algumas evidências e interesses que contribuíram com a definição temática. Identifica como objetivo geral: analisar dificuldades demonstradas por alunos de disciplinas matemáticas ao resolver uma questão sobre sequências numéricas, visando à elaboração, aplicação e análise de um conjunto de atividades sobre esse conteúdo, para uso em cursos de formação de professores.

A pesquisa teve como objetivos específicos: analisar os erros mais frequentes cometidos por alunos de disciplinas matemáticas de três turmas de graduação e uma turma de pós-graduação, na resolução de uma questão sobre sequências numéricas; identificar os registros de representação utilizados por esses alunos; desenvolver e analisar um conjunto de atividades de ensino de sequências numéricas para acadêmicos de Licenciatura em Matemática.

Inicialmente, realizou-se um levantamento de ementas de cursos de Licenciatura em Matemática do Rio Grande do Sul, a fim de verificar se o conteúdo de sequências é ensinado em tais cursos; pôde-se verificar que esse conteúdo é apresentado nos cursos de Licenciatura em Matemática em diferentes disciplinas, evidenciando a sua presença e importância na formação de professores, visto que praticamente todos os cursos analisados incluem o conteúdo de sequências em alguma disciplina do curso de Licenciatura em Matemática.

No segundo capítulo, encontra-se a fundamentação teórica sobre os temas abordados, englobando o conteúdo de sequências numéricas, a revisão de livros didáticos, os registros

\footnotetext{
${ }^{1}$ Doutoranda em Ensino de Ciências e Matemática - ULBRA, Mestre em Ensino de Ciências e Matemática UNIFRA, Especialista em Metodologia de Ensino de Matemática - UNIASSELVI e Licenciada em Matemática - URI. E-mail: miriamfzh@gmail.com
} 
de representação semiótica e uma revisão de literatura sobre os temas elencados. Por sua vez, no terceiro capítulo foram indicados os procedimentos metodológicos da pesquisa, possuindo como aporte teórico a Teoria dos Registros de Representação Semiótica, a metodologia de investigação da Análise de Erros e o aporte da Análise de Conteúdo de Bardin para auxiliar a interpretação dos dados empíricos da pesquisa.

No quarto capítulo apresentaram-se os resultados da pesquisa, que incluem o levantamento de ementas dos cursos de Licenciatura em Matemática, a aplicação do teste e os dados obtidos da análise, sendo que foram definidas quatro turmas para desenvolver a pesquisa, duas compostas por acadêmicos dos cursos de Licenciatura em Matemática das duas Instituições de Ensino Superior envolvidas no projeto do CNPq, uma por acadêmicos de um curso de Sistema de Informação de uma das instituições e, por fim, uma turma composta por Licenciados em Matemática, cursando Mestrado na área de Ensino de Matemática em uma das instituições. A eles foi aplicado um teste, composto por uma questão sobre sequências numéricas, cujas respostas foram analisadas à luz da Teoria dos Registros de Representação Semiótica. Como resultado, observou-se que a conversão da linguagem natural para a algébrica, em qualquer dos itens, foi realizada pela maior parte dos alunos que não deixaram em branco qualquer dos itens. Já a conversão da linguagem natural para a figural foi usada como recurso inicial para compreender o problema.

A análise das respostas dos alunos de Licenciatura em Matemática foi apresentada a duas professoras de um dos cursos de Licenciatura em Matemática, posteriormente foi realizada uma entrevista com elas, para saber sua opinião sobre os erros cometidos, sobre as atividades desenvolvidas e em relação à importância de usar diferentes registros de representação semiótica para trabalhar com o conteúdo de sequências numéricas.

Partindo da análise dos dados encontrados na pesquisa, foi elaborado um conjunto de atividades sobre sequências ${ }^{1}$, para ser utilizado em sala de aula de cursos de Licenciatura em Matemática ou mesmo em turmas de educação básica, bem como um objeto de aprendizagem a ser usado em laboratório de informática, sobre o mesmo conteúdo. Para a seleção das respectivas questões, também se levou em consideração a abordagem dos diferentes tipos de registros de representação semiótica.

Importante salientar que o conjunto de atividades propostas pode ser explorado como uma introdução ao estudo de sequências se for apresentado em um curso de Licenciatura em Matemática, mas também pode ser trabalhado dentro do estudo de metodologias de ensino, em cursos de formação inicial ou continuada.

No capítulo 6, são apresentadas as considerações finais, as referências e os 
apêndices. Salienta-se que todos os objetivos da pesquisa foram satisfeitos. A autora considera que o trabalho foi relevante para a sua formação acadêmica, visto que conseguiu desenvolver e adquirir novos conhecimentos teóricos e práticos, relacionados com a teoria dos Registros de Representação Semiótica e com a metodologia de ensino e pesquisa da análise de erros.

No decorrer da pesquisa, foi possível identificar e analisar as principais dificuldades dos alunos, refletir sobre o ensino e aprendizagem, sobre alguns aspectos relacionados à formação de futuros professores de Matemática. Entre os métodos avaliativos, destaca-se a análise de erros como suporte para mudanças na prática educativa, especialmente em cursos de formação de professores.

Acredita-se que esta pesquisa possa servir como sugestão para os cursos de formação de professores de Matemática, contribuindo com a instrumentalização do trabalho com padrões desde a Educação Básica, assim como promover algumas reflexões pertinentes a diferentes níveis de ensino sobre o processo educativo do conteúdo de sequências numéricas, podendo vir a contribuir com futuras pesquisas acadêmicas relacionadas com a temática. 